\title{
Changes in the respiratory microbiome during acute exacerbations of idiopathic pulmonary fibrosis
}

\author{
Philip L. Molyneaux ${ }^{1,2}$, Michael J Cox ${ }^{1}$, Athol U. Wells ${ }^{2}$, Ho Cheol Kim³, Wonjun Ji', William O. C. Cookson', \\ Miriam F. Moffatt ${ }^{1}$, Dong Soon Kim ${ }^{3+}$ and Toby M. Maher ${ }^{1,2,4^{*}+}$
}

\begin{abstract}
Acute exacerbations of idiopathic pulmonary fibrosis (AE-IPF) have been defined as events of clinically significant respiratory deterioration with an unidentifiable cause. They carry a significant mortality and morbidity and while their exact pathogenesis remains unclear, the possibility remains that hidden infection may play a role. The aim of this pilot study was to determine whether changes in the respiratory microbiota occur during an AE-IPF. Bacterial DNA was extracted from bronchoalveolar lavage from patients with stable IPF and those experiencing an AE-IPF. A hyper-variable region of the $16 \mathrm{~S}$ ribosomal RNA gene (16S rRNA) was amplified, quantified and pyrosequenced. Culture independent techniques demonstrate AE-IPF is associated with an increased BAL bacterial burden compared to stable disease and highlight shifts in the composition of the respiratory microbiota during an AE-IPF.
\end{abstract}

Keywords: Idiopathic pulmonary fibrosis, Acute exacerbation, Bacterial infection, $16 \mathrm{~S}$

\section{Background}

Current diagnostic criteria for acute exacerbations of idiopathic pulmonary fibrosis (AE-IPF) clearly distinguish them from exacerbations of other respiratory diseases [1]. Prior to the latest iteration of the guidelines diagnosis of an AE-IPF specifically required the exclusion of any infective trigger [2]. The exact pathogenesis, however, remains unknown and it is currently unclear whether AE-IPF represent an accelerated phase of the underlying fibroproliferative process or an exaggerated lung injury response to unidentified preceding or coexistent infection [3]. There are a number of factors supporting a role for infection; i) seasonal patterns exist with increased AE-IPF occurring during the winter months, ii) respiratory tract infections in individuals with IPF confer a mortality risk indistinguishable from that seen with acute exacerbations [4], iii) post mortem examination in cases of confirmed infection frequently discloses diffuse alveolar damage identical to that seen

\footnotetext{
* Correspondence: t.maher@imperial.ac.uk

${ }^{\dagger}$ Equal contributors

${ }^{1}$ National Heart and Lung Institute, Imperial College, London, UK

${ }^{2}$ Royal Brompton Hospital, London, UK

Full list of author information is available at the end of the article
}

during an AE-IPF and, iv) immunosuppression is associated with an increased rate of acute exacerbations [5].

Given the limited sensitivity of culture-dependant clinical microbiology techniques it is plausible that many episodes of apparent AE-IPF arise as the sequelae of infection [6]. While the role of viruses in AE-IPF has been extensively investigated [7] there has been little focus on a potential role for bacteria, despite recent evidence that bacterial burden is increased in the IPF lung and changes in the microbiome relate to disease outcomes $[8,9]$. In order to explore changes in the bronchoalveolar lavage (BAL) microbiota during an AE-IPF, $16 \mathrm{~S}$ rRNA gene qPCR and pyrosequencing were performed on both stable and exacerbation samples in subjects with IPF.

\section{Materials \\ Study design}

Patients with AE-IPF undergoing bronchoscopy were recruited prospectively from the University of Ulsan, Korea. A diagnosis of IPF was made, according to international guidelines [10], following multidisciplinary team discussion. A diagnosis of an acute exacerbation was made based on the established criteria at that time [2]. 
All subjects with acute exacerbation had negative clinical evaluation for infection including; respiratory syncytial virus, influenza $A$ and $B$, human parainfluenza viruses, adenovirus, human cytomegalovirus, herpes simplex, varicella-zoster virus and standard bacterial culture. Control patients with stable IPF (defined by the absence of acute exacerbation) were recruited alongside AE-IPF patients and underwent bronchoscopy at the time of diagnosis. All bronchoscopies were performed as part of routine clinical care within the first $48 \mathrm{~h}$ of admission and ideally before the commencement of any antibiotics. However, a number of AE-IPF subjects did receive antibiotics before lavage. Written informed consent was obtained from all subjects and the study received approval from the local institutional review board.

\section{Bronchoscopy}

Fibre-optic bronchoscopy with BAL was performed as part of routine clinical evaluation, and in subjects undergoing AE-IPF was undertaken within $48 \mathrm{~h}$ of admission to hospital. Bronchoscopy was performed according to a standard operating procedure [11] and BAL was performed in a single sub-segment of the right middle lobe, with at least $100 \mathrm{ml}$ of sterile saline instilled. BAL fluid was examined for the presence of macrophages to confirm access of the alveolar compartment, and the absence of ciliated epithelium was used to exclude large airway contamination.

\section{DNA extraction}

The samples were processed at the time of collection and subsequently stored at $-80{ }^{\circ} \mathrm{C}$ as separate cell pellets and supernatants. The samples, one $2 \mathrm{ml}$ aliquot of BAL supernatant and one BAL pellet including supernatant, were thawed and then centrifuged at $20,000 \mathrm{~g}$ for $15 \mathrm{~min}$, to pellet cell debris and bacteria. Each pellet was then re-suspended and combined allowing genomic DNA to be isolated using the MP Bio FastDNA ${ }^{\circ}$ SPIN Kit for Soil (http://www.mpbio.com) as previously described [12].

\section{S rRNA gene $\mathrm{qPCR}$ and Pyrosequencing}

The V3-V5 region of the bacterial 16S rRNA gene was amplified using the $357 \mathrm{~F}$ forward primer and the 926R reverse primer for both $16 \mathrm{~S}$ rRNA gene qPCR and pyrosequencing as previously described [12].

\section{Statistical analysis}

Analysis was undertaken as described previously [8] with continuous variables presented as means ( \pm Standard Deviation $[\mathrm{SD}]$ ), and categorical variables as proportions. Metastats was used to perform non-parametric $t$-test comparisons of microbial communities between groups, with $P$-values corrected by multiple hypotheses testing using the FDR approach of Benjamini and Hochberg [13]. We restricted testing to Operational Taxonomic Units (OTUs) that had a differing mean abundance between cases and controls of more than $1 \%$ of the total. Shannon's entropy [14] (alpha diversity index) and weighted and unweighted UniFrac distances [15] (beta diversity) were calculated in QIIME. Differences between subject groups were evaluated with the use of the Mann-Whitney test for continuous variables and Fisher's exact test for categorical variables. The statistical significance of association of variables with an AE-IPF was assessed using a stepwise backward elimination logistic regression process to select among potential covariates for inclusion in the final model. All analyses were performed with the use of SPSS (version 21) and R (http:// cran.r-project.org/). A two-sided $P$ value of less than 0.05 was considered to indicate statistical significance.

\section{Results}

Twenty patients with acute exacerbations of IPF and 15 matched control patients with stable IPF were enrolled at the University of Ulsan in Seoul, Korea (Table 1) [7]. The patients were matched for age, sex, smoking history and baseline lung function. There was no significant difference in the use of immunosuppressive therapy between groups. Patients had negative lavage bacterial culture and respiratory virus screens. There was no significant difference in lavage cell count between either group. There was a significantly higher neutrophil count in the lavage of AE-IPF subjects compared to controls $(23.7 \pm 4.39$ vs. $9.0 \pm 3.27 ; P=0.037)$ that occurred at the expense of monocytes $(40.9 \pm 3.73$ vs. $70.3 \pm 3.73 ; P=$ $<0.005)$. There was no significant difference in the lymphocyte, basophil or eosinophil cell populations. The average survival in the AE-IPF cohort was $187( \pm 65)$ days compared to $568( \pm 70)$ days in the controls $(P=$ $0.0004)$. Thirteen (65\%) of the subjects experiencing an exacerbation died in the following 60 days and six patients received mechanical ventilation.

All 35 samples yielded genomic DNA and underwent amplification of the V3-V5 region of the 16S rRNA gene.

Table 1 Baseline Characteristics of the Subjects

\begin{tabular}{lll}
\hline & $\begin{array}{l}\text { Stable IPF } \\
(N=15)\end{array}$ & $\begin{array}{l}\text { AE-IPF } \\
(N=20)\end{array}$ \\
\hline Age (yr) & $66.7( \pm 6.4)$ & $66.3( \pm 6.7)$ \\
Female Sex - number (\%) & $3(20 \%)$ & $5(25 \%)$ \\
Smoking (Ever v Never) - number (\%) & $11(73 \%)$ & $15(75 \%)$ \\
FVC - \% & $79.0( \pm 21)$ & $80.0( \pm 19)$ \\
DLCO - \% & $69.0( \pm 14)$ & $66.0( \pm 16)$
\end{tabular}

Details are provided for stable IPF and for AE-IPF cases. All lung function data was recorded when stable. There were no significant differences between either cohort. Data are mean \pm Standard Deviation. DLCO, carbon monoxide diffusion capacity; FVC, forced vital capacity 
Three of the samples (two exacerbation samples and one stable sample) yielded insufficient 16S rRNA gene product to undergo pyrosequencing and were therefore excluded. All of the samples in this study were extracted, amplified and sequenced together in a single batch, to control for the potential effects of batch and operator variability. Sequence data has been submitted to the European Nucleotide Archive and is available under accession number PRJEB18649 (http://www.ebi.ac.uk/ena/ data/view/PRJEB18649). In addition the denoised reads, OTU table and clinical data are available to download from the EMBL-EBI BioStudies database under accession number S-BSST12 (https://www.ebi.ac.uk/biostudies/studies/S-BSST12).

AE-IPF subjects had on average $4.9 \times 10^{9}(\mathrm{SD} \pm 7.9 \times$ $10^{9}$ ) copies of the $16 \mathrm{~S}$ rRNA gene per $\mathrm{ml}$ of BAL. This was over four times higher than the copy number in the stable IPF subjects $(P=0.012)$ (Fig. 1$)$. Negative control samples yielded a bacterial burden close to or below the lower limit of qPCR quantification (1,000 copies/ml). Bacterial burden remained significantly associated with a diagnosis of AE-IPF, using a stepwise logistic regression incorporating sex, age and smoking status $\left(P=0.029, \mathrm{R}^{2}\right.$ 0.51 ) and correlated strongly with disease state (Spearman's $\rho=0.45, P=0.008$ ), indicating that total bacterial load is significantly associated with an AE-IPF.

At phylum level the microbiota of the stable IPF subjects was dominated by Firmicutes (34\%), Proteobacteria (32\%), Bacteroidetes (16\%) and Actinobacteria (10\%). Although the same phyla predominated in the AE-IPF subjects, Proteobacteria accounted for over $40 \%$ of the total reads $(P=0.12)$, with the percentage of reads assigned to Firmicutes, Bacteroidetes, and Actinobacteria dropping compared to the stable subjects $(29,14$ and $6 \%$

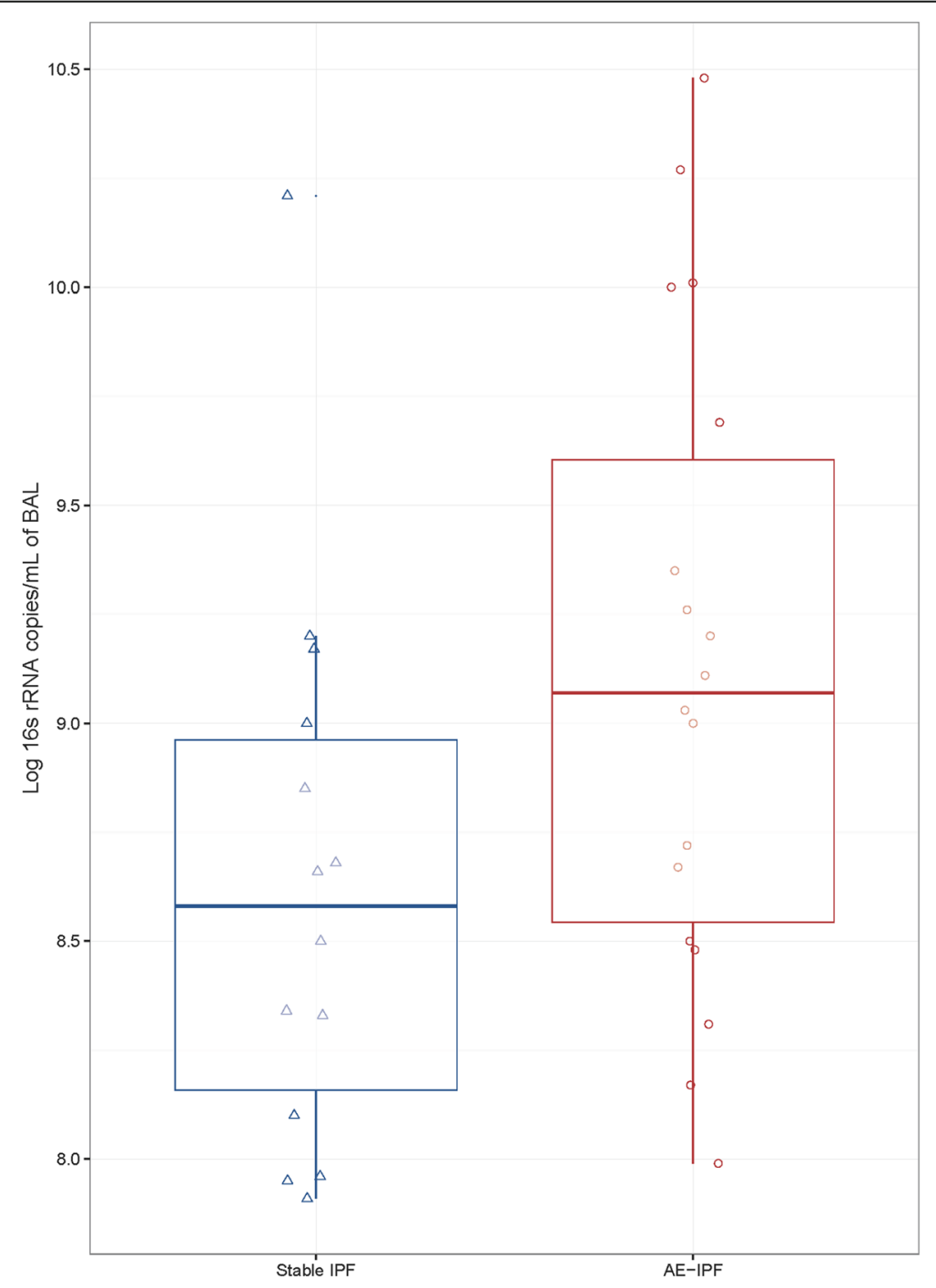

Fig. 1 Bacterial load in acute exacerbation of IPF compared with stable disease 


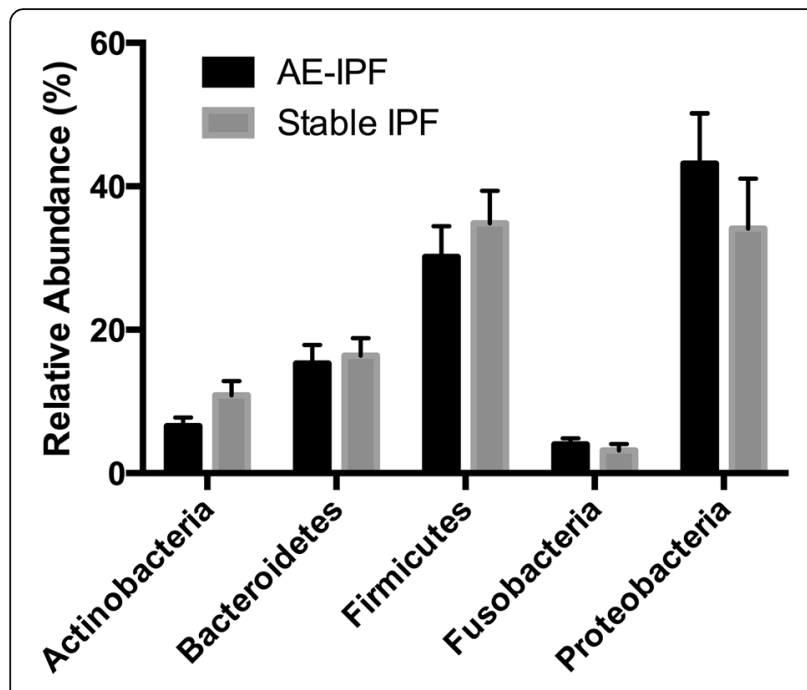

Fig. 2 Changes in specific bacterial species in acute exacerbations of IPF compared with stable disease

respectively) (Fig. 2). Comparison at an OTU level identified that within the Proteobacteria phylum there was a higher relative abundance of two potentially pathogenic OTUs in the AE-IPF samples; Campylobacter sp. $(P=$ $0.02)$ and Stenotrophomonas sp. $(P=0.03)$. By contrast, significantly higher numbers of a Veillonella sp. $(P<$ $0.01)$ were present in the stable IPF samples. Han and colleagues [16] found both Streptococcus and Staphylococcus OTUs to be associated with IPF disease progression. Here we do not find any significant difference in the proportion of either species between the stable and exacerbation groups.

\section{Discussion}

AE-IPF is associated with an increased BAL bacterial burden compared to stable IPF. The bacterial communities of the stable Korean IPF subjects were found to contain Streptococcus, Prevotella, Veillonella, Haemophilus and Pseudomonas which are all commonly found in the airways of healthy individuals as well as subjects with asthma, COPD and IPF $[8,9,12,17,18]$. Following an AE-IPF there was a notable change in the microbiota with an increase in two potentially pathogenic Proteobacterial OTUs; Campylobacter sp. and Stenotrophomonas sp., coupled with a significant decrease in Veillonella sp..

Campylobacter, although best known as a gastrointestinal pathogen, has previously been identified in the respiratory microbiota of individuals with severe COPD. Its presence in the respiratory microbiota is likely to arise from silent micro-aspiration of gastric contents and strengthens the already identified association of reflux and aspiration with acute exacerbations in a subgroup of patients [19]. Stenotrophomonas, a Gram-negative bacterium, is known to colonise the respiratory tract of patients with chronic lung disease [18]. It is a potential respiratory pathogen and although most commonly associated with intubated and ventilated patients, it is responsible for respiratory infections in cystic patients and patients with chronic health conditions.

It is important to note that there are a number of limitations in relation to this study. The very nature of AEIPF make them severe and unpredictable events and therefore microbiological sampling is often difficult and carries a high morbidity. This is evident by the fact that six out of 20 AE-IPF subjects in the current study were intubated at the time of sampling, however, when the data here were analyzed with these subjects excluded, the observed differences remained unchanged. These patients were prospectively recruited and sampled, however, the microbiome work was retrospective and bronchoscopy samples were collected out of clinical necessity within the first $24 \mathrm{~h}$ of admission. This was ideally before the commencement of any antibiotics, however, a number of AE-IPF subjects did receive antibiotics therapy prior to sampling. Despite this antibiotic therapy there was a significant increase in the bacterial burden and changes in the microbiota, suggesting that antibiotic therapy does not completely confound the observed differences associated with exacerbation, as it might be expected that antibiotics would reduce the bacterial burden. Future studies will have to concentrate on overcoming the challenge of prospective sampling; something which has yet to be achieved in this rapidly progressive and often fatal complication of IPF. However, until we understand the aetiology of these events in more detail the clinical urge will remain to start empiric anti-microbial therapy at the earliest opportunity when managing a patient with an AE-IPF.

There are currently no precise methods of ruling out upper airway bronchoscopic carry over of bacteria, even with upper airway samples [20]. In this study the same protocols, procedures and kit batches were used for stable and AE-IPF samples, rendering any potential contamination consistent across comparative groups and therefore unlikely to have influenced the results. Specifically none of the OTUs demonstrated a correlation with a lower bacterial burden, which can indicate a contaminant [21] and the inclusion of negative reagent controls, which yielded bacterial burden close to or below the lower limit of qPCR quantification, also demonstrates that the $\mathrm{qPCR}$ results are not a sampling or processing artefact.

Unlike exacerbations of other respiratory conditions which are truly acute events, the onset of an exacerbation in IPF is more insidious with a gradual worsening over days to weeks. Consequently by the time of presentation any triggering viruses may no longer be detectable, despite exhaustive searching [22]. Viruses have been shown to impact the respiratory microbiome, 
causing changes which persist for weeks, so the differences identified could represent the consequence of an unidentified preceding viral insult [12].

\section{Conclusions}

In summary differences in specific OTUs and bacterial burden suggest that bacteria may play a causative role in some AE-IPF. The apparent translocation of bacteria usually confined to the gastrointestinal tract also suggests a role for aspiration in the development of acute exacerbations. This pilot study had a number of limitations and a prospective study with paired samples prior to and during an exacerbation will be required to test the hypotheses generated by this data. Nonetheless, our observations challenge the current paradigm for AE-IPF and provide a rationale for clinical trials of prophylactic antibiotics as a strategy to prevent acute exacerbations in individuals with IPF.

\section{Abbreviations}

16S rRNA: 165 ribosomal RNA gene; AE-IPF: Acute exacerbation of IPF; BAL: Bronchoalveolar lavage; OTUs: Operational Taxonomic Units

\section{Acknowledgements}

Not Applicable.

\section{Funding}

PLM was an Asmarley Clinical Research Fellow. Funding was from the Asmarley Trust and the Wellcome Trust. TMM is supported by an NIHR Clinician Scientist Fellowship (NIHR Ref: CS-2013-13-017). The project was supported by the NIHR Respiratory Disease Biomedical Research Unit at the Royal Brompton and Harefield NHS Foundation Trust, the AHSC Biomedical Research Centre at Imperial College London and the National Institutes of Health (HL097163 and HL092870). The funders had no role in study design, data collection and analysis, decision to publish, or preparation of the manuscript.

\section{Availability of data and materials}

All the data from this manuscript is publically available.

\section{Authors' contributions}

PLM planned the project, designed and performed experiments, analyzed the data and wrote the manuscript; MJC performed statistical analyses, interpreted the results and helped write the manuscript; TMM, MFM and WOC conceived the microbiological studies of IPF, planned the project, designed experiments, analyzed the data and wrote the manuscript. HCK, WJ collected the samples and the clinical data of the subjects and DSK conceived the design of the study and recruited patients. All authors reviewed, revised and approved the manuscript for submission.

\section{Competing interests}

The authors declare that they have no competing interests.

\section{Consent for publication}

Not Applicable.

\section{Ethics approval and consent to participate}

Written informed consent was obtained from all subjects for participation and publication and the study received approval from the local institutional review board.

\section{Financial disclosure}

The funders had no role in study design, data collection and analysis, decision to publish, or preparation of the manuscript.

\section{Author details}

${ }^{1}$ National Heart and Lung Institute, Imperial College, London, UK. ${ }^{2}$ Royal Brompton Hospital, London, UK. ${ }^{3}$ Asan Medical Center, University of Ulsan, Seoul, Korea. ${ }^{4}$ Fibrosis Research Group, Inflammation, Repair \& Development Section, NHLI, Sir Alexander Fleming Building, Imperial College, London SW7 $2 \mathrm{AZ}, \mathrm{UK}$.

Received: 18 June 2016 Accepted: 16 January 2017

Published online: 01 February 2017

\section{References}

1. Collard HR, Ryerson CJ, Corte TJ, Jenkins G, Kondoh Y, Lederer DJ, Lee JS, Maher TM, Wells AU, Antoniou KM, Behr J, Brown KK, Cottin V, Flaherty KR, Fukuoka J, Hansell DM, Johkoh T, Kaminski N, Kim DS, Kolb M, Lynch DA, Myers JL, Raghu G, Richeldi L, Taniquchi H, Martinez FJ. Acute exacerbation of idiopathic pulmonary fibrosis. An international working group report. Am J Respir Crit Care Med. 2016;194:265-75.

2. Collard HR, Moore BB, Flaherty KR, Brown KK, Kaner RJ, King TE, Lasky JA, Loyd JE, Noth I, Olman MA, Raghu G, Roman J, Ryu JH, Zisman DA, Hunninghake GW, Colby TV, Egan JJ, Hansell DM, Johkoh T, Kaminski N, Kim DS, Kondoh Y, Lynch D a, Müller-Quernheim J, Myers JL, Nicholson AG, Selman MMM, Toews GB, Wells AU, Martinez FJ, et al. Acute exacerbations of idiopathic pulmonary fibrosis. Am J Respir Crit Care Med. 2007;176:636-43.

3. Maher TM. The diagnosis of idiopathic pulmonary fibrosis and its complications. Expert Opin Med Diagn. 2008;2:1317-31.

4. Song JW, Hong S-B, Lim C-M, Koh Y, Kim DS. Acute exacerbation of idiopathic pulmonary fibrosis: incidence, risk factors and outcome. Eur Respir J. 2011;37:356-63.

5. Raghu G, Anstrom KJ, King TE, Lasky JA, Martinez FJ. Prednisone, azathioprine, and $\mathrm{N}$-acetylcysteine for pulmonary fibrosis. N Engl J Med. 2012;366:1968-77.

6. Molyneaux PL, Maher TM. The role of infection in the pathogenesis of idiopathic pulmonary fibrosis. Eur Respir Rev. 2013;22:376-81.

7. Wootton SC, Kim DS, Kondoh Y, Chen E, Lee JS, Song JW, Huh JW, Taniguchi H, Chiu C, Boushey H, Lancaster LH, Wolters PJ, DeRisi J, Ganem D, Collard HR. Viral infection in acute exacerbation of idiopathic pulmonary fibrosis. Am J Respir Crit Care Med. 2011;183:1-30.

8. Molyneaux PL, Cox MJ, Willis-Owen SAG, Mallia P, Russell KE, Russell AM, Murphy E, Johnston SL, Schwartz DA, Wells AU, Cookson WOC, Maher TM, Moffatt MF. The Role of Bacteria in the Pathogenesis and Progression of Idiopathic Pulmonary Fibrosis. Am J Respir Crit Care Med. 2014;190(8):90613.

9. Han MK, Zhou Y, Murray S, Tayob N, Noth I, Lama VN, Moore BB, White ES, Flaherty KR, Huffnagle GB, Martinez FJ. Lung microbiome and disease progression in idiopathic pulmonary fibrosis: an analysis of the COMET study. Lancet Respir Med. 2014;i:1-9.

10. Raghu G, Collard HR, Egan JJ, Martinez FJ, Behr J, Brown KK, Colby TV, Cordier J-FJ-F, Flaherty KR, Lasky J a, Lynch D a, Ryu JH, Swigris JJ, Wells AU, Ancochea J, Bouros D, Carvalho C, Costabel U, Ebina M, Hansell DM, Johkoh T, Kim DS, King TE, Kondoh Y, Myers J, Muller NL, Nicholson AG, Richeldi L, Selman M, Dudden RF, et al. An official ATS/ERS/JRS/ALAT statement: idiopathic pulmonary fibrosis: evidence-based guidelines for diagnosis and management. Am J Respir Crit Care Med. 2011;183:788-824.

11. Meyer KC, Raghu G, Baughman RP, Brown KK, Costabel U, du Bois RM, Drent M, Haslam PL, Kim DS, Nagai S, Rottoli P, Saltini C, Selman M, Strange C, Wood B. An official American Thoracic Society clinical practice guideline: the clinical utility of bronchoalveolar lavage cellular analysis in interstitial lung disease. Am J Respir Crit Care Med. 2012;185:1004-14.

12. Molyneaux PL, Mallia P, Cox MJ, Footitt J, Willis-Owen SAG, Homola D, Trujillo-Torralbo M-B, Elkin S, Kon OM, Cookson WOC, Moffatt MF, Johnston SL. Outgrowth of the bacterial airway microbiome after rhinovirus exacerbation of chronic obstructive pulmonary disease. Am J Respir Crit Care Med. 2013;188:1224-31.

13. White JR, Nagarajan N, Pop M. Statistical methods for detecting differentially abundant features in clinical metagenomic samples. PLoS Comput Biol. 2009;5:e1000352.

14. Shannon CE. A mathematical theory of communication. ACM SIGMOBILE Mob Comput Commun Rev. 2001;5:3

15. Lozupone C, Hamady M, Knight R. UniFrac-an online tool for comparing microbial community diversity in a phylogenetic context. BMC Bioinformatics. 2006;7:371. 
16. Han MK, Zhou Y, Murray S, Tayob N, Noth I, Lama VN, Moore BB, White ES, Flaherty KR, Huffnagle GB, Martinez FJ. Lung microbiome and disease progression in idiopathic pulmonary fibrosis: an analysis of the COMET study. Lancet Respir Med. 2014;2:448-56.

17. Hilty M, Burke C, Pedro H, Cardenas P, Bush A, Bossley C, Davies J, Ervine A, Poulter L, Pachter L, Moffatt MF, Cookson WOC. Disordered microbial communities in asthmatic airways. PLoS One. 2010;5:e8578.

18. Erb-Downward JR, Thompson DL, Han MK, Freeman CM, McCloskey L, Schmidt L a, Young VB, Toews GB, Curtis JL, Sundaram B, Martinez FJ, Huffnagle GB. Analysis of the lung microbiome in the "healthy" smoker and in COPD. PLoS One. 2011;6:e16384.

19. Lee JS, Song JW, Wolters PJ, Elicker BM, King TE, Kim DS, Collard HR. Bronchoalveolar lavage pepsin in acute exacerbation of idiopathic pulmonary fibrosis. Eur Respir J. 2012;39:352-8.

20. Dickson RP, Erb-Downward JR, Martinez FJ, Huffnagle GB. The microbiome and the respiratory tract. Annu Rev Physiol. 2016;78:481-504.

21. Jervis-Bardy J, Leong LEX, Marri S, Smith RJ, Choo JM, Smith-Vaughan HC, Nosworthy E, Morris PS, O'Leary S, Rogers GB, Marsh RL. Deriving accurate microbiota profiles from human samples with low bacterial content through post-sequencing processing of Illumina MiSeq data. Microbiome. 2015;3:19.

22. Beasley $\mathrm{V}$, Joshi PV, Singanayagam A, Molyneaux PL, Johnston SL, Mallia P. Lung microbiology and exacerbations in COPD. Int J Chron Obstruct Pulmon Dis. 2012;7:555-69.

\section{Submit your next manuscript to BioMed Central} and we will help you at every step:

- We accept pre-submission inquiries

- Our selector tool helps you to find the most relevant journal

- We provide round the clock customer support

- Convenient online submission

- Thorough peer review

- Inclusion in PubMed and all major indexing services

- Maximum visibility for your research

Submit your manuscript at www.biomedcentral.com/submit 